\title{
Long-term treatment of chronic obstructive pulmonary disease with salmeterol and the additive effect of ipratropium
}

\author{
J.A. van Noord*, D.R.A.J. de Munck**, Th.A. Bantje***, W.C.J. Hop ${ }^{+}$, \\ M.L.M. Akveld ${ }^{++}$, A.M. Bommer ${ }^{+}$
}

Long-term treatment of chronic obstructive pulmonary disease with salmeterol and the additive effect of ipratropium. J.A. van Noord, D.R.A.J. de Munck, Th.A. Bantje, W.C.J. Hop, M.L.M. Akveld, A.M. Bommer. CERS Journals Ltd 2000.

ABSTRACT: The efficacy and safety of salmeterol alone was compared with the combination of salmeterol plus ipratropium and with placebo during long-term treatment in patients with stable chronic obstructive pulmonary disease. In addition, the single-dose effect in response to the first dose of treatment was studied over $12 \mathrm{~h}$.

The patients ( $n=144$; age $64 \pm 7$ yrs, forced expiratory volume in one second (FEV1) $44 \pm 11 \%$ pred) participated in a three-centre double-blind double-placebo parallel group study and were randomized after a run-in period of 2 weeks to receive either salmeterol $50 \mu \mathrm{g}$ b.i.d., salmeterol $5 \mu \mathrm{g}$ b.i.d. plus ipratropium $40 \mu \mathrm{g}$ q.i.d. or placebo for a period of 12 weeks.

The single-dose study demonstrated that salmeterol produced a significant increase in FEV1 (peak of 7\% pred) and specific airway conductance ( $\mathrm{s} G$ aw) (maximum of $60 \%$ baseline) for $\geq 12 \mathrm{~h}$. The combination of salmeterol plus ipratropium elicited a greater bronchodilator response $(11 \%$ and $94 \%$ increases respectively) than salmeterol alone during the first $6 \mathrm{~h}$ after inhalation. During treatment there were significant improvements in daytime symptom scores and morning peak expiratory flow in both the salmeterol and the salmeterol plus ipratropium groups $(p<0.001)$, with an associated decrease in the use of rescue salbutamol. Improvements in FEV1 and sGaw were greater in the salmeterol plus ipratropium group than in the patients receiving only salmeterol. Thirty-five patients had an exacerbation; $11(23 \%)$ in the salmeterol group (versus placebo $\mathrm{Ns}$ ), six (13\%) in the salmeterol plus ipratropium group (versus placebo $p<0.01)$ and $18(36 \%)$ in the placebo group.

In conclusion, in patients with severe stable chronic obstructive pulmonary disease, long-term treatment with either salmeterol alone or salmeterol plus ipratropium is safe and effective. There was added benefit from the combination therapy in terms of improvement in airways obstruction, but not for improvement in symptom control or need for rescue salbutamol.

Eur Respir J 2000; 15: 878-885.
Depts of Respiratory Diseases, *Atrium medisch centrum, Heerlen, **St Joseph Hospital, Veldhoven and $* * *$ Ignatius Hospital, Breda, ${ }^{+}$Dept of Epidemiology and Biostatistics, Erasmus University, Rotterdam and ${ }^{++}$GlaxoWellcome, Zeist, the Netherlands.

Correspondence: J.A. van Noord, Dept of Respiratory Diseases, Atrium medisch centrum, Henri Dunantstraat 5, 6419 PC Heerlen, The Netherlands. Fax: 31 455767534 .

Keywords: Chronic obstructive pulmonary disease ipratropium salmeterol

Received: March 191998

Accepted after revision November 71998
Chronic obstructive pulmonary disease (COPD) is defined as a disease state characterized by the presence of airflow obstruction, due to chronic bronchitis or emphysema, and is generally progressive but may be partially reversible [1]. The goals of pharmacotherapy in this disorder are to induce bronchodilation and facilitate expectoration in order to improve symptoms, prevent recurrent exacerbations and so enhance the quality of life [2]. In patients with stable COPD, the spirometric response to bronchodilators such as $\beta_{2}$-agonists, anticholinergic drugs and methylxanthines is at best very modest. However, even in the absence of significant bronchodilation, an improvement in symptoms and exercise tolerance can be demonstrated [3].

Salmeterol xinofoate, a long-acting $\beta_{2}$-agonist, has been shown in single-dose studies to induce a spirometric improvement over a 12-h period in patients with COPD [46]. In addition, three studies in patients with COPD over periods of 1-3 months have found that treatment with salmeterol produced an improvement in lung function and daily symptom scores and was associated with a clinically significant gain in quality of life [7-10]. Recently MAHLER et al. [11], comparing inhaled salmeterol and ipratropium in patients with COPD over a 12 -week period, found that salmeterol was better than ipratropium at improving lung function. To date, long-term studies on combination therapy with salmeterol and ipratropium bromide are not available. A number of trials have shown that, in patients with stable COPD, the combination of short-acting $\beta_{2}$ agonists and ipratropium may be beneficial [12], and the combination of salmeterol and ipratropium may have additive effects and long-term benefits.

This study was designed to compare the efficacy and safety of salmeterol either alone or in combination with ipratropium bromide with that of placebo during a 12-week treatment period in patients with stable COPD. In addition, the single-dose effect in response to the first dose of the treatment was studied over a period of $12 \mathrm{~h}$. 


\section{Methods}

\section{Patients}

Patients had to meet the following criteria to be recruited for the study: 1) current or exsmokers with a smoking history equivalent to 10 pack-yrs and with COPD according to American Thoracic Society criteria [1]; 2) aged 40-75 yrs; 3) no change in medication for COPD in the preceding 6 weeks and no major changes in smoking habits during the last 6 months; and 4) a forced expiratory volume in one second (FEV1) of $\leq 75 \%$ of the predicted value after inhalation of $200 \mu \mathrm{g}$ salbutamol via metered dose inhaler (MDI). Exclusion criteria included the following: a history of asthma, allergic rhinitis, atopy or a total blood eosinophil count of $>500$ cells $\cdot \mathrm{mm}^{-3}$; respiratory disease other than COPD; any clinically significant concurrent disease; and oxygen therapy.

\section{Study design}

The study had a randomized, double-blind double-placebo, parallel group design and was performed at three centres in the Netherlands. The study was approved by the Medical Ethics Committees of all the participating hospitals. Written informed consent was obtained from all patients before any study procedure was undertaken. The study had a run-in period of 2 weeks, a treatment period of 12 weeks and a follow-up period of 2 weeks. There were six scheduled visits to the clinic: at the start of the run-in period (visit 1), at the start of treatment (visit 2), after 4, 8 and 12 weeks of treatment (visits 3-5) and 2 weeks after stopping treatment (visit 6) for follow-up. At the start of the run-in period, all $\beta_{2}$-agonists and anticholinergics were withdrawn. The patients continued to take the permitted medication for their COPD in stable doses, including methylxanthines, oral steroids and inhaled steroids up to 2,000 $\mu \mathrm{g} \cdot \mathrm{day}^{-1}$ and fluticasone propionate up to $1,000 \mu \mathrm{g} \cdot \mathrm{day}^{-1}$. Patients were given salbutamol as rescue medication. At the end of the run-in period (visit 2), patients were eligible for randomization if they fulfilled the following inclusion criteria: 1 ) an FEV 1 of $\leq 65 \%$ pred and $\geq 0.75 \mathrm{~L}$ at visit 1 or 2 , bronchodilators having been withheld for an appropriate period, i.e. $\geq 4 \mathrm{~h}$ for short-acting bronchodilators, $\geq 24 \mathrm{~h}$ for long-acting $\beta_{2}$-agonists and $36 \mathrm{~h}$ for methylxanthines; 2 ) an $\mathrm{FEV} 1 /$ forced vital capacity (FVC) ratio of $\leq 60 \%$ at visit 1 or 2 ; and 3) A daytime symptom score of $\geq 2$ on at least 4 out of 7 days during the run-in period (see Diary card section).

The eligible patients were randomly assigned to treatment with 1) salmeterol $50 \mu \mathrm{g}$ plus ipratropium bromide matched placebo; 2) salmeterol $50 \mu \mathrm{g}$ plus ipratropium bromide $40 \mu \mathrm{g}$; or 3 ) salmeterol-matched placebo plus ipratropium bromide-matched placebo. After randomization, the first dose of the study medication was given and lung function was measured for $12 \mathrm{~h}$. Subsequently, the patient was treated with the same regimen for a period of 12 weeks. Salmeterol or placebo matched to salmeterol was inhaled b.i.d. at 08:00 and 22:00. Ipratropium or placebo matched to ipratropium was inhaled q.i.d. at the following time points 08:00, 13:.00, 17:00, and 22:00 h. All medications were inhaled from an MDI attached to an aerosol chamber (Volumatic $\mathbb{R}$; GlaxoWellcome, UK).

\section{Measurements}

First dose of treatment. Airway resistance (Raw), specific airway conductance ( $\mathrm{s} G \mathrm{aw}), \mathrm{FEV} 1$ and $\mathrm{FVC}$ were obtained at baseline and $0.5,1,2,3,4,5,6,8,10$ and $12 \mathrm{~h}$ after inhalation of the trial drugs. FEV1 and FVC were recorded at the mouth using a pneumotachograph with electronic integration. The best of three adequate measurements was retained. Raw and $\mathrm{s} G$ aw were measured in a pressure-compensated integrated flow plethysmograph (SensorMedics 2800 Autobox; SensorMedics Corp., Yorba Linda, CA, USA) as the slopes of the chords between inspiratory and expiratory flows of $0.5 \mathrm{~L} \cdot \mathrm{s}^{-1}$ at a respiratory frequency of $0.5 \mathrm{~Hz}$. The means of three measurements are reported. In addition blood pressure and cardiac frequency were obtained at baseline and 1, 2, 3, 4, 5, 6, 8 and $12 \mathrm{~h}$ after inhalation.

Twelve-week treatment. Diary card. During the run-in and treatment periods, all patients completed a daily diary card, recording their morning and evening peak expiratory flow (PEF), daytime and night-time symptoms and use of rescue salbutamol. PEF was measured using a Personal Best peak flow meter (Healthscan Products Inc., Cedar Grove, NJ, USA) between 07:00 and 08:00 $\mathrm{h}$ before taking the study medication and between 19:00 and 20:00 h. The best of three measurements was retained. The use of rescue medication within $4 \mathrm{~h}$ of the measurements was also recorded. The following symptom scores were used. Daytime symptom score: 0: no symptoms at rest or on exertion; 1: no symptoms at rest but symptoms on moderate exertion, e.g. walking quickly, climbing stairs, rushing out to work; 2 : no symptoms at rest but symptoms on mild exertion, e.g. getting dressed or washed; 3: minimal symptoms at rest, e.g. while sitting reading or watching the television; 4 : moderate symptoms at rest, e.g. while sitting reading or watching the television; and 5: severe symptoms at rest, i.e. patient unable to carry out any activity requiring exertion. This daytime symptom score has been used previously in COPD [7]. Night-time symptom score: 0 : no symptoms during the night; 1 : symptoms causing patient to wake once or wake early; 2: symptoms causing patient to wake twice or more (including waking early); 3: symptoms causing patient to be awake most of the night; and 4: symptoms so severe that patient did not sleep at all. This five-point symptom score for night-time use has also been used previously $[9,13]$.

Clinic visits. At each scheduled visit, details of adverse events, exacerbations and withdrawals were recorded and Raw, sGaw, FEV1 and FVC were measured. All lung function measurements were performed between 08:00 and 12:00 $\mathrm{h}$ after the morning dose of the study medication. At each visit, the response to salbutamol $200 \mu \mathrm{g}$ was measured $15 \mathrm{~min}$ after inhalation. An exacerbation was defined as an increase in symptoms requiring either a course of oral corticosteroids or antibiotics or a hospital admission. This change in medication was at the investigator's discretion.

\section{Statistical analysis}

Comparison of percentages between groups was done using Fisher's exact test. For the single dose part of the study, the change (per cent) from baseline of FEV1 and $\mathrm{s} G$ aw was determined at each timepoint. To compare treatment groups, the area under the curve (AUC) for these changes was calculated using the trapezoid rule. In a few 
patients $(n=9)$, all but one after placebo, the single-dose study had to be interrupted due to shortness of breath. In these patients the last observation made was carried forward to determine the AUC. Analysis of variance (ANOVA) was used to compare mean AUCs between treatment groups. The same test was used to compare treatment groups at the different time points.

The change from baseline (per cent) of the lung function test outcomes at the visits after 4,8 and 12 weeks of treatment were compared between and within groups using repeated measures ANOVA using the BioMedical Data Processing (BMDP) Statistical Software package [14]. To evaluate diary card outcomes (symptom scores, PEF, and use of rescue medication), the days during treatment were grouped according to the time at which visits at the clinic occurred, i.e. weeks 1-4, 5-8 and 9-12. Mean values during these treatment periods were determined, and compared to baseline values obtained during the run-in period. For individual patients, values obtained in a particular treatment period were considered evaluable only if the number of diary card days completed by the patient was $\geq 7$. Repeated-measures ANOVA was used to compare between- and within- group changes from baseline. The limit for statistical significance was set at two-sided $\mathrm{p}=$ 0.017 (i.e. $0.05 / 3$ ) in the pairwise comparison of treatment groups, according to Bonferroni's principle [15]. In the case of withdrawal, all data obtained prior to that point were included in all analyses.

\section{Results}

Of the 177 patients recruited for the study, 29 were excluded before randomization because of ineligibility, and four were excluded from analysis due to protocol violations. Of the remaining 144 patients, 47 received salmeterol, 47 salmeterol plus ipratropium and 50 placebo. The characteristics of these patients are given in table 1 . The groups were well balanced and there were no significant differences among the three groups in demographic data and baseline lung function. Medication usage was comparable among the three groups. In total, 20 patients were withdrawn from the study during treatment, eight in the placebo group, seven in the salmeterol group and five in the salmeterol plus ipratropium group (NS). The reasons for withdrawal were: exacerbation of COPD (three patients in the salmeterol group, two in the salmeterol plus ipratropium group and four in the placebo group), adverse events not considered to be drug related (four patients), missed visits (one patient), poor compliance (one patient), and others (five patients). The data of the withdrawn patients were included in the (intention-to-treat) analysis.

\section{First-dose study}

The time/response curves after the first dose of salmeterol and salmeterol plus ipratropium over a period of $12 \mathrm{~h}$ after inhalation are shown in figure 1 . There were no significant differences in baseline FEV1, FVC and sGaw among the three groups. After inhalation of salmeterol there was a mean \pm SEM peak increase in FEV1 of $7 \pm 0.7 \%$ pred after $2 \mathrm{~h}$, followed by a plateau. After $12 \mathrm{~h}$, the improvement was still $2 \pm 1 \%$ pred. Salmeterol plus ipratropium produced a peak increase in FEV1 of $11 \pm 0.8 \%$ pred after $2 \mathrm{~h}$. After $12 \mathrm{~h}$, the improvement was $3 \pm 0.8 \%$ pred. The improvement in FVC in the two active treatment groups was in line with that in FEV1. After salme-
Table 1. - Baseline characteristics of the randomized patients

\begin{tabular}{|c|c|c|c|}
\hline & Salmeterol & $\begin{array}{l}\text { Salmeterol plus } \\
\text { ipratropium }\end{array}$ & Placebo \\
\hline Patients $n$ & 47 & 47 & 50 \\
\hline Sex M/F \% & $89 / 11$ & $88 / 12$ & $86 / 14$ \\
\hline Current smoker \% & 49 & 57 & 58 \\
\hline Age yrs & $65 \pm 6$ & $63 \pm 7$ & $63 \pm 7$ \\
\hline \multicolumn{4}{|l|}{ Visit 1 (screening) } \\
\hline $\begin{array}{l}\text { FEV1 L } \\
\text { Reversibility \% }\end{array}$ & $1.3 \pm 0.4$ & $1.4 \pm 0.4$ & $1.3 \pm 0.4$ \\
\hline$\%$ baseline & $13 \pm 10$ & $16 \pm 11$ & $15 \pm 9$ \\
\hline \% FEV1 pred & $6 \pm 4$ & $7 \pm 5$ & $6 \pm 3$ \\
\hline \multicolumn{4}{|l|}{ Visit 2 (baseline) } \\
\hline FEV1 L & $1.2 \pm 0.4$ & $1.2 \pm 0.4$ & $1.1 \pm 0.3$ \\
\hline FEV1 \% pred & $42 \pm 10$ & $41 \pm 12$ & $38 \pm 10$ \\
\hline FVC L & $2.8 \pm 0.8$ & $3.0 \pm 0.8$ & $2.8 \pm 0.7$ \\
\hline FEV1/FVC \% & $43 \pm 8$ & $42 \pm 9$ & $41 \pm 9$ \\
\hline Raw $\mathrm{kPa} \cdot \mathrm{L}^{-1} \cdot \mathrm{s}$ & $0.63 \pm 0.23$ & $0.65 \pm 0.23$ & $0.72 \pm 0.30$ \\
\hline $\mathrm{s} G$ aw $\mathrm{kPa} \cdot \mathrm{L}^{-1} \cdot \mathrm{s}$ & $0.35 \pm 0.18$ & $0.33 \pm 0.13$ & $0.29 \pm 0.09$ \\
\hline \multicolumn{4}{|l|}{$\begin{array}{l}\text { Concurrent } \\
\text { medication }\end{array}$} \\
\hline$\beta_{2}$-agonists* $\mathrm{n}$ & 45 & 52 & 51 \\
\hline Anticholinergics* $n$ & 23 & 17 & 22 \\
\hline $\begin{array}{l}\text { Methylxanthines n } \\
\text { Inhaled }\end{array}$ & 9 & 5 & 4 \\
\hline $\begin{array}{l}\text { corticosteroids } \mathrm{n} \\
\text { Oral }\end{array}$ & 38 & 35 & 38 \\
\hline corticosteroids $n$ & 5 & 5 & 1 \\
\hline Mucolytics n & 16 & 12 & 18 \\
\hline
\end{tabular}

Data are mean $\pm \mathrm{SD} .{ }^{*}$ : withdrawn at visit $1 . \mathrm{F}$ : female; M: male. FEV1: forced expiratory volume in one second; \%FEV1 pred: percentage of predicted FEV1; FVC: forced vital capacity; \% pred: percentage of predicted value; Raw: airway resistance; sGaw: specific airway conductance.

terol, there was a maximum increase in $s G$ aw of $60 \pm 7.2 \%$ baseline after $4 \mathrm{~h}$, followed by a slowly declining plateau, the increase in $\mathrm{s} G$ aw after $12 \mathrm{~h}$ being $25 \pm 5.6 \%$ baseline. The combination of salmeterol and ipratropium led to a maximum increase in $\mathrm{s} G$ aw of $94 \pm 8.9 \%$ baseline after $2 \mathrm{~h}$, the increase after $12 \mathrm{~h}$ also being $25 \pm 5.1 \%$ baseline.

The mean AUCs of the parameters investigated (FEV1, FVC and $\mathrm{s} G$ aw) were significantly greater in both the salmeterol and the salmeterol plus ipratropium groups than in the placebo group $(\mathrm{p}<0.001)$. Furthermore, the AUCs of FEV1 and $s G$ aw after salmeterol plus ipratropium, compared with those after salmeterol, were in favour of the former group $(\mathrm{p}<0.05)$. The AUCs of FVC did not significantly differ between the salmeterol and salmeterol plus ipratropium groups. Considering each single time point after inhalation, there were no longer any significant differences in FEV1, FVC and sGaw between the salmeterol and the salmeterol plus ipratropium groups after $6 \mathrm{~h}$. There were no significant treatment effects on cardiac frequency and blood pressure.

\section{Twelve-week treatment}

Day-and night-time symptom scores. The mean daytime symptom score during the run-in period did not differ among the three groups (fig. 2). Throughout the treatment period there was a mean \pm SEM decrease from $1.9 \pm 0.1$ to $1.7 \pm 0.1$ in the placebo group NS, from $2.0 \pm 0.1$ to $1.4 \pm 0.1$ $(\mathrm{p}<0.001)$ in the salmeterol group and from $2.0 \pm 0.1$ to 
a)

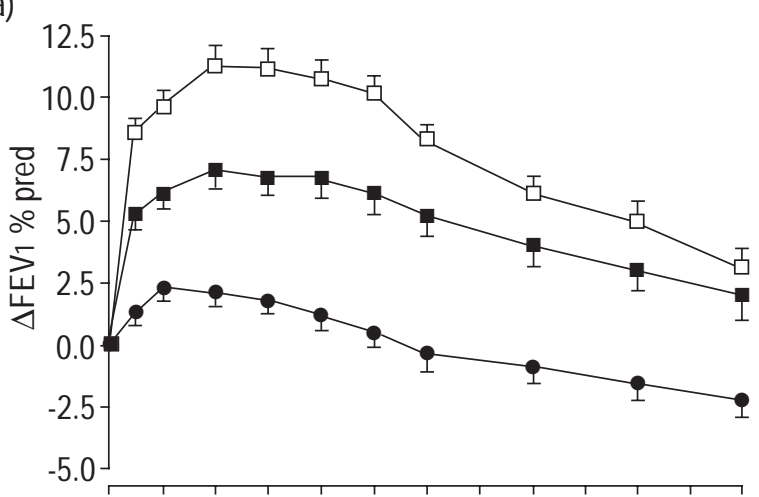

b)

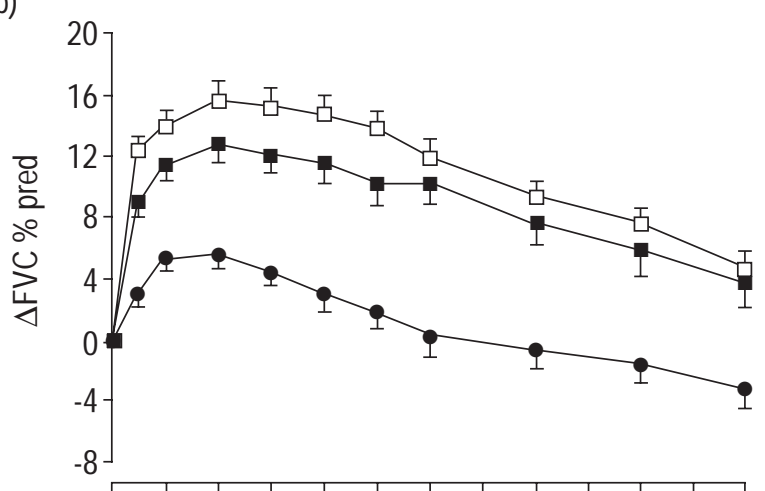

c)

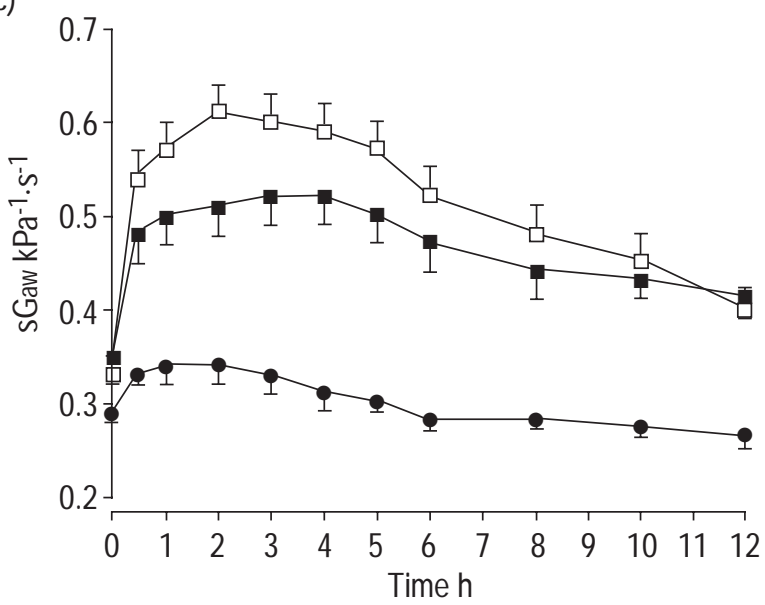

Fig. 1. - Change $(\Delta)$ in: a) forced expiratory volume in one second (FEV1); b) forced vital capacity (FVC); and c) absolute values of specific airway conductance (sGaw) during $12 \mathrm{~h}$ after salmeterol ( $\square$ ), salmeterol plus ipratropium $(\square)$ and placebo $(\mathbf{O})$. Data are presented as mean \pm SEM. \% pred: percentage of the predicted value.

$1.3 \pm 0.1 \quad(p<0.001)$ in the salmeterol plus ipratropium group. There was a significant difference in the change from the run-in period in the daytime symptom score between the salmeterol and the placebo groups $(\mathrm{p}<0.005)$ and between the salmeterol plus ipratropium and placebo groups $(p<0.001)$, but not between the salmeterol and the salmeterol plus ipratropium groups.

In addition, analysis was made of the mean \pm SEM percentage of days with a minimal level of symptoms (score $\leq 1$ ). During the run-in period, this amounted $14 \pm 2.9 \%$ in the salmeterol group, $14 \pm 3.0 \%$ in the salmeterol plus ipratropium group and $17 \pm 3.7 \%$ in the placebo group. During treatment, the percentages increased to $49 \pm 3.0$ for the salmeterol group, $57 \pm 3.0$ for the salmeterol plus ipratropium group and $34 \pm 4.0$ for the placebo group, all changes being significant $(\mathrm{p}<0.05)$. Improvements in both active treatment arms were better than in the placebo group $(\mathrm{p}<0.05)$, but no significant difference was observed between the salmeterol and the salmeterol plus ipratropium groups. The mean \pm SEM night-time symptom score during the run-in period was $0.7 \pm 0.1$ in the placebo group, $0.8 \pm 0.1$ in the salmeterol group and $0.8 \pm 0.1$ in the salmeterol plus ipratropium group. No change was found in the mean scores during treatment for all groups. The percentage of nights without symptoms at baseline was not different among the three groups, $52 \pm 6.0$ in the placebo group, $54 \pm 5.9$ in the salmeterol group and $50 \pm 6.4$ in the salmeterol plus ipratropium group. No significant changes were observed in these percentages during treatment for all groups.

Rescue medication. The patients were permitted to use salbutamol as rescue medication during both the run-in and the treatment periods. Compared with placebo, treatment with both salmeterol and salmeterol plus ipratropium were associated with a higher percentage of days and nights without use of additional salbutamol $(\mathrm{p}<0.01)$ (fig. 2). No difference was observed between the two active treatment arms $(p=0.35)$. During the run-in period, the mean \pm SEM percentages of days with additional use of salbutamol were $98 \pm 1.8,97 \pm 2.2$ and $93 \pm 3.2$ for placebo, salmeterol and salmeterol plus ipratropium, respectively. During the treatment period, these values decreased to $74 \pm 5.0,34 \pm$ 5.5 and $27 \pm 5.5$, respectively. At baseline, the percentages of nights with rescue bronchodilator usage were $37 \pm 6.1$, $37 \pm 6.3$ and $50 \pm 6.9$ for placebo, salmeterol and salmeterol plus ipratropium, respectively. During the treatment period these percentages were reduced to $33 \pm 6.3,17 \pm 2.9$ and $24 \pm 4.1 \%$, respectively.

Peak expiratory flow measurements. Improvements in morning PEFs were significantly better in both active treatment groups than in the placebo group $(p<0.001)$, whereas no difference was observed between the salmeterol and the salmeterol plus ipratropium groups (fig. 3). During the treatment period, meansem morning PEF changed from $238 \pm 9 \mathrm{~L} \cdot \mathrm{min}^{-1}$ to $236 \pm 9 \mathrm{~L} \cdot \mathrm{min}^{-1}$ in the placebo group, from $246 \pm 9$ to $262 \pm 11 \mathrm{~L} \cdot \mathrm{min}^{-1}$ in the salmeterol group and from $252 \pm 11$ to $277 \pm 12 \mathrm{~L} \cdot \mathrm{min}^{-1}$ in the salmeterol plus ipratropium group. Also, the changes in evening PEFs (measured before the evening dose of salmeterol but after the 17:00 h dose of ipratropium) were in favour of both active treatment arms compared with placebo $(p<0.001)$, whereas the improvement was better in the salmeterol plus ipratropium group than in the salmeterol group $(\mathrm{p}<0.01)$. Evening PEF changed from $259 \pm 10$ to $253 \pm 10 \mathrm{~L} \cdot \mathrm{min}^{-1}$ in the placebo group, from $257 \pm 10$ to $271 \pm 11 \mathrm{~L} \cdot \mathrm{min}^{-1}$ in the salmeterol group and from $271 \pm 10$ to $297 \pm 11 \mathrm{~L} \cdot \mathrm{min}^{-1}$ in the salmeterol plus ipratropium group.

Clinic lung function. During the 12-week treatment period, the mean \pm SEM increase in FEV1 was $1 \pm 0.9 \%$ pred for the placebo, $5 \pm 0.9 \%$ pred for the salmeterol and $8 \pm 0.8 \%$ pred for the salmeterol plus ipratropium treatment groups (fig. 4). All differences between the three groups were significant $(\mathrm{p}<0.01)$. The change in FVC was $4 \pm 1.2 \%$ 

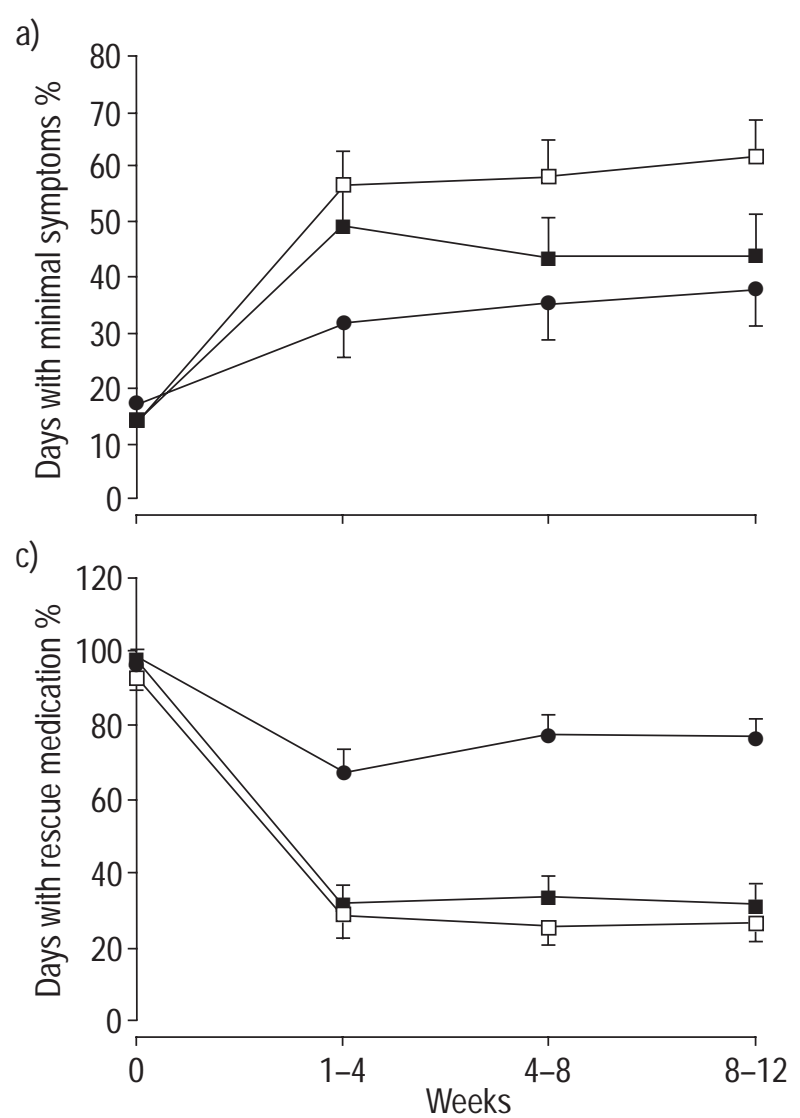

b)

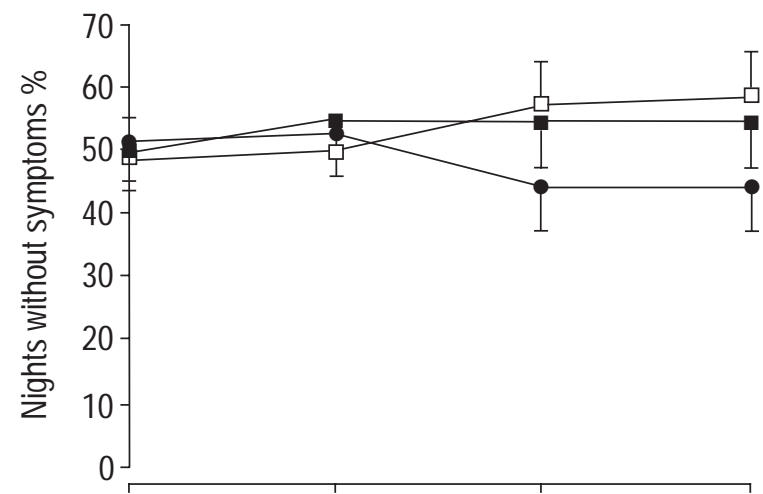

d)

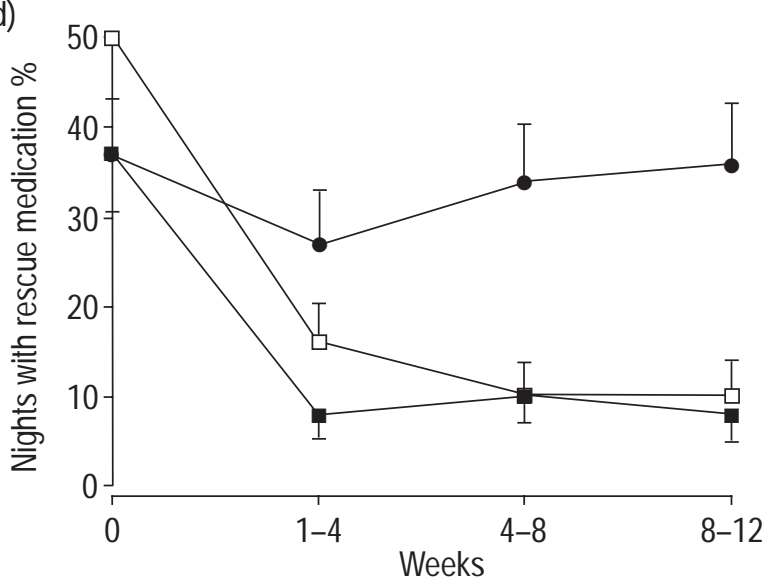

Fig. 2. - Percentage of: a) days with minimal (score $\leq 1)$ symptoms; b) nights without symptoms; c) days with rescue medication; and d) nights with rescue medication per 4-week period before and during treatment with salmeterol ( $\square$ ), salmeterol plus ipratropium ( $\square$ ) and placebo ( $)$. Data are presented as mean \pm SEM.

pred after placebo, $7 \pm 1.2 \%$ pred after salmeterol and $12 \pm 1.2 \%$ after salmeterol plus ipratropium. The differences between salmeterol plus ipratropium versus salmeterol alone and between salmeterol plus ipratropium versus placebo were both significant $(p<0.01)$, whereas there was no significant difference between the change in FVC after placebo and salmeterol $(\mathrm{p}=0.055)$. The mean \pm SEM increase in $\mathrm{s} G$ aw from baseline was $16 \pm 6 \%$ after placebo, $36 \pm 6 \%$ after salmeterol and $61 \pm 6 \%$ after salmeterol plus ipratropium, all differences between the three groups being significant $(\mathrm{p}<0.01)$. The maximum improvement in FEV1, FVC and $\mathrm{s} G$ aw was reached at visit 3 after 4 weeks of treatment and was sustained throughout the treatment period in the salmeterol and salmeterol plus ipratropium groups. In contrast, in the placebo group, FEV1, FVC and $\mathrm{s} G$ aw continued to improve, albeit at a lower level, during the treatment period. At visits 3, 4 and 5, i.e. after 4,8 and 12 weeks of treatment, inhalation of salbutamol $200 \mu \mathrm{g}$ produced an additional improvement in FEV1 in all groups (fig. 5). This increase in FEV1 postsalbutamol was greater in the placebo than in the salmeterol and salmeterol plus ipratropium groups $(p<0.01)$. There were no significant differences in mean FEV1 after salbutamol at any visit among the three groups. In other words, active treatment with salmeterol or salmeterol plus ipratropium did not change the maximum attainable FEV1 after salbutamol.

Adverse events and exacerbations. Both active treatments were well tolerated. The reported incidence and nature of possible and probably drug-related side-effects were similar among the three groups. The most common drug-related adverse events were headache (six patients in the salmeterol plus ipratropium group, four in the salmeterol group and 11 in the placebo group) and cough after inhalation (two patients in the salmeterol plus ipratropium group, three in the salmeterol group and three in the placebo group). In the salmeterol plus ipratropium group, one patient reported muscle cramps. During the 12-week treatment period, 35 patients experienced a COPD exacerbation, $18(36 \%)$ in the placebo group, $11(23 \%)$ in the salmeterol group and six $(13 \%)$ in the salmeterol plus ipratropium group. The only significant difference was that between the salmeterol plus ipratropium group and the placebo group $(\mathrm{p}<0.01)$.

\section{Discussion}

At the start of the 12-week treatment period, the timeresponse curve was evaluated after the first dose of the active treatment and placebo regimens. The results demonstrate that, in patients with stable COPD and severe airflow obstruction, $50 \mu \mathrm{g}$ of salmeterol produces a significant improvement in lung function as assessed by FEV1 and $\mathrm{s} G$ aw, with a peak effect after $2-4 \mathrm{~h}$ and a duration of action of $\geq 12 \mathrm{~h}$. In addition, the combination of salmeterol $50 \mu \mathrm{g}$ and ipratropium bromide $40 \mu \mathrm{g}$ elicited a greater bronchodilator response than salmeterol alone during the first $6 \mathrm{~h}$ after inhalation. The present results with salmeterol are in line with those of CAzzola et al. [4]. These authors, 


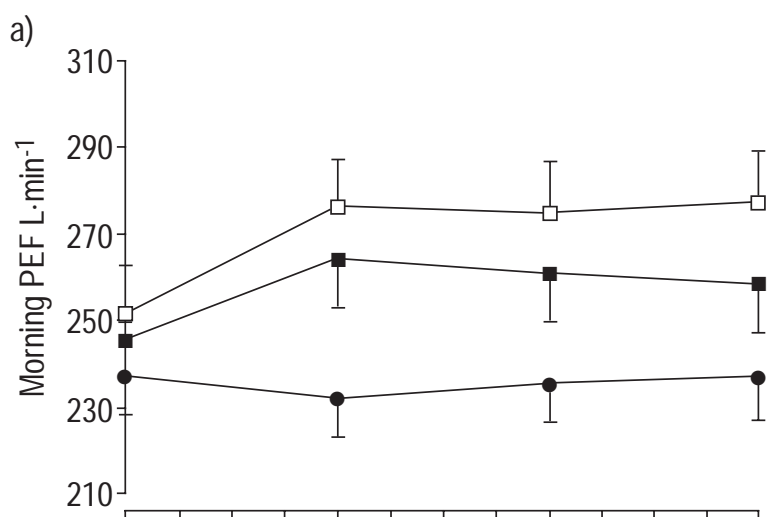

b)

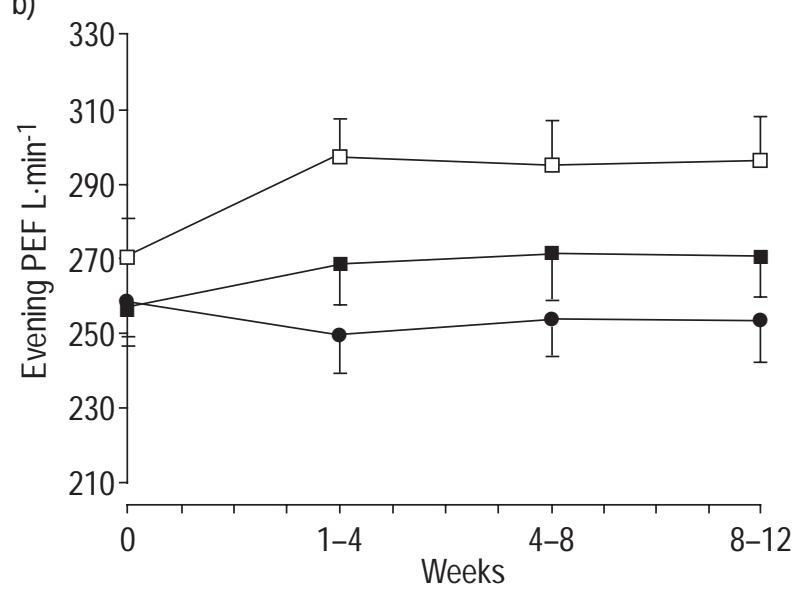

Fig. 3. - Peak expiratory flow (PEF) in: a) the morning; and b) the evening over 4-week periods before and during treatment with salmeterol ( $\square$ ), salmeterol plus ipratropium $(\square)$ and placebo ( Data are presented as mean \pm SEM.

comparing single doses of 25,50 and $75 \mu \mathrm{g}$ salmeterol in patients with COPD, found that all doses induced a significant improvement in FEV1 over the $12 \mathrm{~h}$ monitoring period. As the results after 50 and $75 \mu \mathrm{g}$ of salmeterol were similar, they suggested that $50 \mu \mathrm{g}$ was the best dose of salmeterol in these patients. It has been shown that this recommended dose of $50 \mu \mathrm{g}$ salmeterol produces a similar [11] or even greater improvement [16] in airway obstruction than the recommended dose of 40 $\mu \mathrm{g}$ ipratropium bromide. To date, only one clinical trial has been carried out on the efficacy of combined administration of salmeterol and ipratropium in COPD. MATERA et al. [17] found that, in an ill-defined group of 12 patients with COPD, combination of salmeterol and ipratropium in the clinically recommended doses did not produce greater bronchodilation than salmeterol alone. However, a number of large clinical trials indicate that combination of the short-acting $\beta_{2}$-agonist albuterol and ipratropium produces better improvement in spirometric indices than either drug taken alone at the recommended doses $[12,18]$. In contrast to the findings of MATERA et al. [17], the present study demonstrated that this was also true for the combination of the long-acting $\beta_{2}$-agonist salmeterol and ipratropium during the first $6 \mathrm{~h}$ after dosing, after which time the additive effect of the shortacting ipratropium presumably diminished.

Changes in lung function during the 12-week treatment period were evaluated in two ways, by measuring clinic lung function after the morning dose and by recording PEF at home before the morning dose. There was a significant improvement in clinic lung function as measured by FEV1 and $\mathrm{s} G$ aw in both the salmeterol and the salmeterol plus ipratropium groups. This improvement was greater in the salmeterol plus ipratropium group than in the salmeterol group, indicating that, in these patients with severe airflow obstruction, the recommended dose of salmeterol alone was not able to achieve maximum bronchodilation and that combination of the two drugs had an additive effect. Moreover, it turned out that, even after salmeterol plus ipratropium at the conventional dose further bronchodilation was still possible with salbutamol. These results are in keeping with those of CAZzOLA et al. [19] who showed that pretreatment with a conventional dose of salmeterol in COPD does not preclude the possibility of inducing further bronchodilation with salbutamol. The hypothesis that higher doses of salmeterol or ipratropium alone could have induced an improvement in airflow obstruction similar to that following the combination of salmeterol and ipratropium was not tested. There are several studies supporting this hypothesis. EASTON et al. [20] demonstrated in COPD that, when either salbutamol or ipratropium was given alone at the maximal dose, both drugs were equally effective and the addition of the second drug did not cause further bronchodilation. IKEDA et al. [21] found that, in patients with COPD, 160 or $240 \mu \mathrm{g}$ ipratropium produced a greater improvement in FEV 1 than 40 or $80 \mu \mathrm{g}$. In line with these results, it was found that there was no difference in the maximum achievable FEV1 after salbutamol in the two treatment arms. It generally follows that the risk of sideeffects increases with increasing doses of any drug. The most important rationale for combination therapy is therefore probable very favourable ratio of efficacy and sideeffects. The incidence of side-effects in the present study during combination treatment was very low indeed.

The present study also demonstrated that, in both active treatment groups, improvement in clinic lung function was maximal after 4 weeks of treatment and remained stable throughout the complete course of the treatment period, confirming that long-term use of salmeterol with or without ipratropium does not lead to tolerance of clinical importance to this long-acting $\beta_{2}$-agonist. Moreover, during treatment there was no change in the bronchodilator response to salbutamol.

Furthermore, only the combination treatment of salmeterol plus ipratropium produced a significant increase in FVC, which can be interpreted as an improvement in air trapping and a diminution of airway closure. The result was not expected a priori as it is generally thought that ipratropium produces its bronchodilating effect mainly in the central airways $[22,23]$.

Unlike clinic lung function, which was measured after the morning dose of the study drugs, morning PEF was measured at home before the morning dose of the study medication. Both salmeterol and salmeterol plus ipratropium produced increases in morning PEF, which were greater than those after placebo but did not differ from each other. Considering the duration of action of ipratropium of $\sim 6-8 \mathrm{~h}$, the long duration of action of the evening dose of salmeterol must account for this increase in trough values of PEF in the morning. This improvement in morning PEF remained stable throughout the 12-week treatment period, indicating an absence of tolerance to the duration 


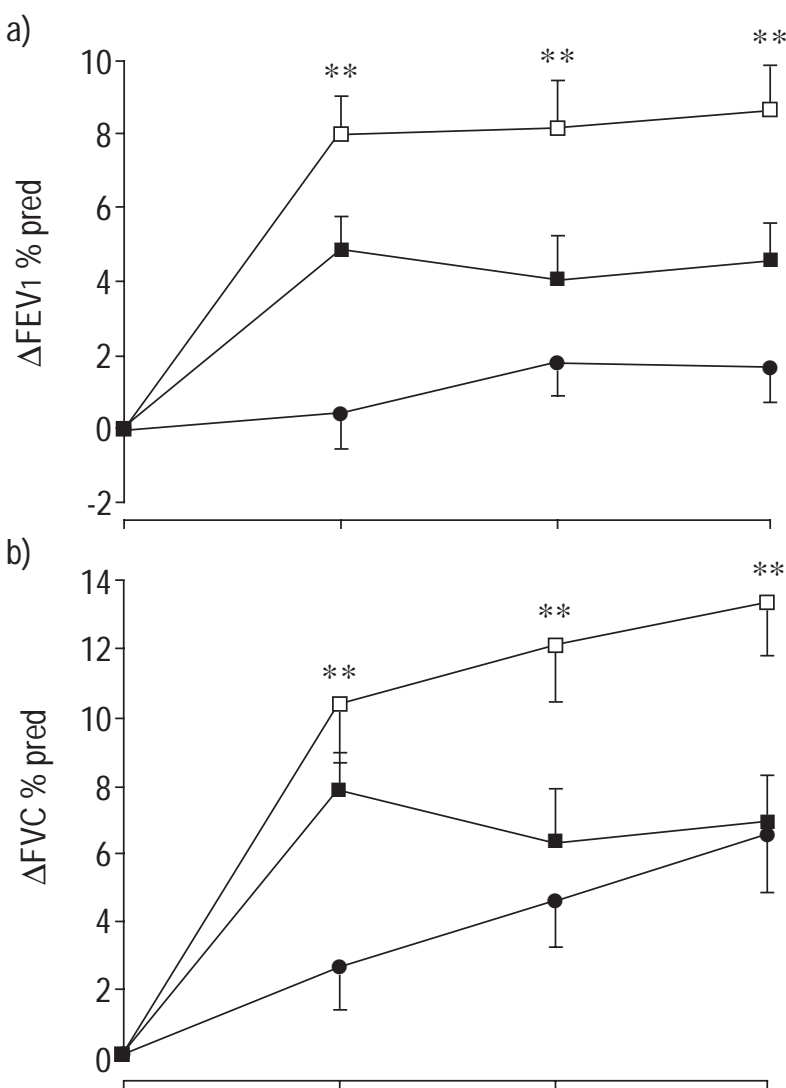

c)

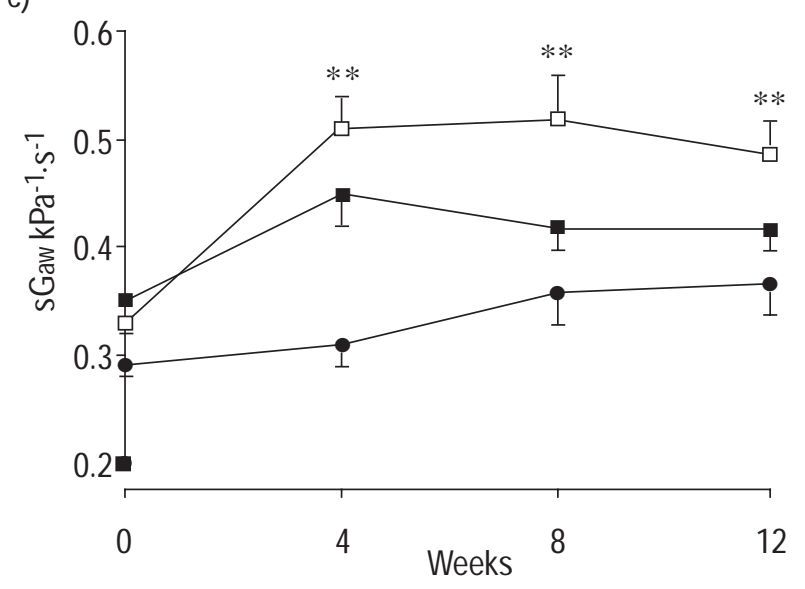

Fig. 4. - Change $(\Delta)$ in: a) forced expiratory volume in one second (FEV1); b) forced vital capacity (FVC); and c) absolute values of specific airway conductance ( $\mathrm{s} G$ aw) after 4, 8 and 12 weeks of treatment with salmeterol ( $\square$ ), salmeterol plus ipratropium $(\square)$, and placebo $(\bullet)$. Data are presented as mean \pm SEM. \% pred: percentage of the predicted value. $* *: \mathrm{p}<0.01$ versus salmeterol alone.

of the bronchodilating effect of salmeterol. Analysis of the evening PEF has little meaning, because measurements were performed before the evening dose of salmeterol but only $2 \mathrm{~h}$ after the inhalation of the evening dose of ipratropium.

It is known that in COPD relations between lung function measurements, symptoms, exercise capacity, walking distance and quality of life are not straightforward. HAY et al. [3] demonstrated that improvements in walking dis- tances and symptoms are unrelated to change in FEV1 after bronchodilator use and routine reversibility testing is not a good predictor of symptomatic benefit in COPD. Several authors have shown that small or even no changes in FEV1 after bronchodilation may nevertheless be associated with an improvement in symptoms and clinically significant gains in health and well-being $[3,6,8]$. WEGNer et al. [24] found that severe COPD could be characterized by three statistically independent entities: 1) exercise capacity, dyspnoea and quality-of-life scores; 2) airflow obstruction; and 3) pulmonary hyperinflation. It is obvious that improvement in airways obstruction is not the most relevant end point of this study and that improving health and well-being is far more important for the patient. Therefore, the primary outcome parameters of the present study were daytime and night-time symptom scores, use of rescue medication and exacerbation rate. It turned out that treatment with both salmeterol and salmeterol plus ipratropium resulted in significant reductions in daytime symptoms, an increase in days with minimal symptoms and a decrease in the use of rescue salbutamol during the day and the night. In contrast to the results of the lung function measurements at home and in the clinic, there were no significant differences between the two active treatment groups. Night-time symptom scores were also recorded, but no difference between the placebo and active treatment groups could be detected. The reason may be that night-time symptom scores were already very low during the run-in period, leaving little room for improvement during the treatment period. The data on exacerbation rates in this study must be interpreted with caution as the treatment was relatively short. However, it turned out that the number of exacerbations was highest in the placebo group and lowest in the salmeterol plus ipratropium group. The patients in this study also completed the Chronic Respiratory Questionnaire and the St George's Respiratory Questionnaire (SGRQ), the results of which were published very recently [25]. It suffices to note here that the only domain that showed an improvement of clinical relevance was the SGRQ symptoms domain in patients receiving salmeterol plus ipratropium bromide. From the literature, little is known about the relationship between diary card scores and health status questionnaires in COPD. Diary cards are suited to close monitoring of the disease and daily application, whereas questionnaires provide intermittent health estimates [26]. In contrast to questionnaires, diary cards have not been validated and tested intensively [26]. This study demonstrates that diary cards including symptom scores and use of rescue medication correlate imperfectly with health status questionnaires.

In conclusion, in patients with chronic obstructive pulmonary disease and severe airflow obstruction long-term treatment both with salmeterol and salmeterol plus ipratropium is effective and safe. There was added benefit of combination therapy with salmeterol plus ipratropium compared with treatment with salmeterol alone in terms of improvement in airways obstruction, but not in terms of improvement in symptom control or in use of rescue salbutamol. In addition, there was some evidence that active treatment, especially with combination therapy, decreased the rate of exacerbations. 

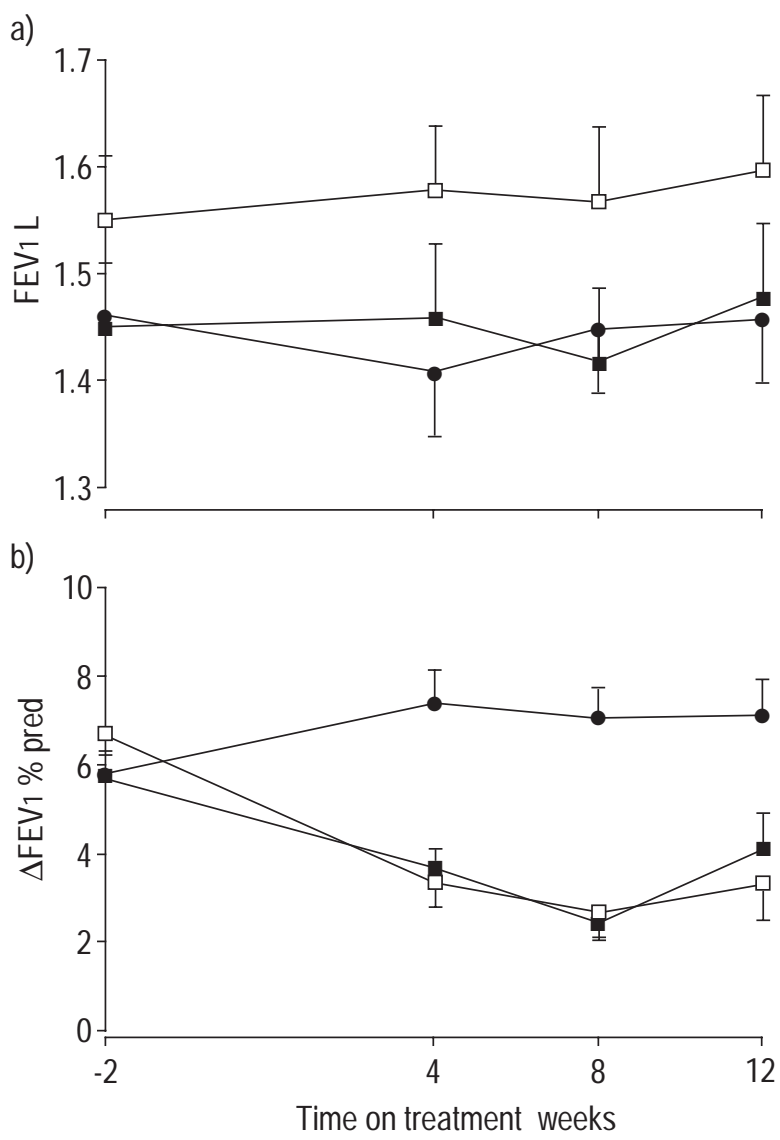

Fig. 5. - a) Forced expiratory volume in one second (FEV1); and b) change $(\Delta)$ in FEV1 after salbutamol at the start of the run-in period and during treatment with salmeterol $(\square)$, salmeterol plus ipratropium $(\square)$, and placebo (O) after 4, 8 and 12 weeks of treatment. Data are presented as mean \pm SEM. $\%$ pred: percentage of the predicted value.

\section{References}

1. American Thoracic Society. Standards for the diagnosis and care of patients with chronic obstructive pulmonary disease. Am J Respir Crit Care Med 1995; 152: S77-S120.

2. Siafakas NM, Vermeire P, Pride NB, et al. Optimal assessment and management of chronic obstructive pulmonary disease (COPD): ERS consensus statement. Eur Respir $J$ 1995; 8: 1398-1420.

3. Hay JG, Stone P, Carter J, et al. Bronchodilator reversibility, exercise performance and breathlessness in stable chronic obstructive pulmonary disease. Eur Respir J 1992; 5: 659664.

4. Cazzola M, Matera MG, Santangelo G, et al. Salmeterol and formoterol in partially reversible severe chronic obstructive pulmonary disease: a dose-response study. Respir Med 1995; 89: $357-362$

5. Cazzola M, Santangelo G, Piccolo A, et al. Effect of salmeterol and formoterol in patients with chronic obstructive pulmonary disease. Pulm Pharmacol 1994; 7: 103107.

6. Cazzola M, Matera MG, Di Pema F, et al. A comparison of bronchodilating effects of salmeterol and oxitropium bromide in stable chronic obstructive pulmonary disease. Respir Med 1998; 92: 354-357.

7. Ulrik CS. Efficacy of inhaled salmeterol in the management of smokers with chronic obstructive pulmonary disease: a single centre randomised, double blind, placebo controlled crossover study. Thorax 1995; 50: 750-754.
8. Grove A, Lipworth BJ, Reid P, et al. Effects of regular salmeterol on lung function and exercise capacity in patients with obstructive airways disease. Thorax 1996; 51: 689-693.

9. Boyd G, Morice AH, Pounsford JC, et al. An evaluation of salmeterol in the treatment of chronic obstructive pulmonary disease (COPD). Eur Respir J 1997; 10: 815-821.

10. Jones PW, Bosh TK. Quality of life changes in COPD patients treated with salmeterol. Am J Respir Crit Care Med 1997; 155: 1283-1289.

11. Mahler DA, Donohue JF, Barbee RA, et al. Efficacy of salmeterol xinafoate in the treatment of COPD. Chest 1999; 115: 957-965.

12. Combivent Inhalation Aerosol Study Group. In chronic obstructive pulmonary disease, a combination of ipratropium and albuterol is more effective than either agent alone. Chest 1994; 105: 1411-1419.

13. Palmer JBD, Stuart AM, Shepherd GL, et al. Inhaled salmeterol in the treatment of patients with moderate-tosevere reversible obstructive airways disease: a three month comparison of the efficacy and safety of twice daily salmeterol (100 mg) with salmeterol (50 mg). Respir Med 1992; 86: 409-417.

14. Schluchter MD. Module 5V. In: Dixon WJ, ed. BMDP Statistical Software Manual. Berkeley, University of California Press, 1990: 1207-1244.

15. Altman DG. Practical Statistics for medical research. London, Chapman \& Hall, 1991: p. 211.

16. Patakas D, Andreadis D, Mavrofridis E, et al. Comparison of the effects of salmeterol and ipratropium bromide on exercise performance and breathlessness in patients with stable chronic obstructive pulmonary disease. Respir Med 1998; 92: 1116-1121.

17. Matera MG, Caputi M, Cazzola M. A combination with clinical recommended dosages of salmeterol and ipratropium is not more effective than salmeterol alone in patients with chronic obstructive pulmonary disease. Respir Med 1996; 90: 497-499.

18. Wilson JD, Serby CW, Menjoge SS, et al. The efficacy and safety of combination bronchodilator therapy. Eur Respir Rev 1996; 6: 39, 286-289.

19. Cazzola M, Di Perna F, Noschese P, et al. Effects of formoterol, salmeterol or oxitropium bromide on airway responses to salbutamol in COPD. Eur Respir $J$ 1998; 11: 1337-1341.

20. Easton PA, Jadue C, Dhingra S, et al. A comparison of the bronchodilating effect of a $\beta_{2}$-adrenergic agent (albuterol) and an anticholinergic agent (ipratropium bromide), given by aerosol alone or in sequence. N Engl J Med 1986; 315: 735739.

21. Ikeda A, Nishimura K, Koyama H, et al. Dose response study of ipratropium bromide aerosol on maximum exercise performance in stable patients with chronic obstructive pulmonary disease. Thorax 1996; 51: 48-53.

22. Ingram RH, Wellman JJ, Mc Fadden ER, et al. Relative contribution of large and small airways to flow limitation in normal subjects before and after atropine and isoproterenol. $J$ Clin Invest 1977; 59: 696-703.

23. Barnes PJ, Basbaum CB, Nadel JA. Autoradiographic localization of autonomic receptors in airway smooth muscle. Marked differences between large and small airways. Am Rev Respir Dis 1983; 127: 758-762.

24. Wegner RE, Jorres RA, Kirsten DK, et al. Factor analysis of exercise capacity, dyspnoea ratings and lung function in patients with severe COPD. Eur Respir J 1994; 7: 725-729.

25. Rutten-van Mölken M, Roos B, Van Noord JA. An empirical comparison of the St George's Respiratory Questionnaire (SGRQ) and the Chronic Respiratory Disease Questionnaire (CRQ) in a clinical trial setting. Thorax 1999; 54: 995-1003.

26. Barley EA, Jones PW. A comparison of global questions versus health status questionnaires as measures of the severity and impact of asthma. Eur Respir J 1999; 14: 591-596. 